\title{
HUBUNGAN ANTARA PEMAKAIAN ALAT KONTRASEPSI SUNTIK DENGAN HIPERTENSI PADA AKSEPTOR KB SUNTIK DI PUSKESMAS HARAPAN RAYA PEKANBARU
}

\author{
Wiwik Norlita, Isnaniar, Elfika Shafitri \\ Program Studi Ilmu DIII Keperawatan Universitas Muhammadiyah Riau \\ Email:wiwiknorlita@umri.ac.id,isnaniar@umri.ac.id,150201007@student.umri.ac.id
}

\begin{abstract}
Hormonal contraceptives such as injectable contraceptives can cause changes in blood pressure. The purpose of this study was to determine the relationship between the use of injectable contraceptives and blood pressure in injectable family planning acceptors at Puskesmas Harapan Raya Pekanbaru. The type of research used is Cross Sectional with accidental sampling sampling technique where the sample in this study were mothers who were found visiting a family planning clinic at Puskesmas Harapan Raya Pekanbaru which amounted to 32 respondents. The results of the study were carried out on July 13-28, 2018, with chi-square statistical tests obtained with normal blood pressure of 25 respondents, hypertension of 7 respondents, and the relationship between types of injectable birth control used with blood pressure ( $p$-value $>0.05$ ) with $p$ value $=0.084$. Conclusion there is no significant relationship between the use of injectable contraceptives and blood pressure in injectable family planning acceptors at Puskesmas Harapan Raya Pekanbaru.
\end{abstract}

Keywords: KB acceptors, injectable contraception, changes in blood pressure.

\begin{abstract}
Abstrak
Alat kontrasepsi hormonal seperti kontrasepsi suntik, dapat menyebabkan terjadinya perubahan tekanan darah. Tujuan dari penelitian ini adalah untuk mengetahui hubungan antara pemakaian alat kontrasepsi suntik dengan tekanan darah pada akseptor KB suntik di Puskesmas Harapan Raya Pekanbaru. Jenis Penelitian yang digunakan adalah Cross Sectional dengan teknik pengambilan sampel accidental sampling dimana sampel dalam penelitian ini adalah ibu- ibu yang dijumpai berkunjung ke poli KB di Puskesmas Harapan Raya Pekanbaru yang berjumlah 32 responden. Hasil Penelitian yang telah dilaksanakan pada tanggal $13-28$ Juli 2018 dengan uji statistik chi-square didapatkan tekanan darah normal 25 responden, hipertensi 7 responden, dan hubungan jenis KB suntik yang digunakan dengan Tekanan Darah didapatkan ( $p$-value $>0,05)$ dengan nilai $\mathrm{p}=0,084$. Kesimpulan tidak terdapat hubungan yang signifikan antara pemakaian alat kontrasepsi suntik dengan tekanan darah pada akseptor KB suntik di Puskesmas Harapan Raya Pekanbaru.
\end{abstract}

Kata Kunci : Akseptor KB, Kontrasepsi Suntik, Perubahan Tekanan Darah. 


\section{PENDAHULUAN}

World Health Organization (WHO) mencatat pada tahun 2012 sedikitnya 839 juta kasus hipertensi, diperkirakan menjadi 1,15 milyar pada tahun 2025 atau sekitar 29 persen dari total penduduk dunia, dimana penderitanya lebih banyak pada wanita (30\%) dibanding pria $(29 \%)$. Secara nasional berdasarkan hasil Riset Kesehatan Dasar (Riskesdas) tahun 2007 menunjukkan tingginya prevalensi penyakit tidak menular, dimana hipertensi yang diawali menempati urutan pertama sebesar 31,7 persen.

Prevalensi hipertensi di Indonesia pada tahun 2013 dilaporkan sebesar 25,8 persen, prevalensi makin tinggi seiring dengan pertambahan umur, khususnya mulai usia $\geq 25$ tahun, lebih tinggi pada perempuan $(28,8 \%)$ dari pada laki-laki $(22,8 \%)$, dan lebih tinggi di kota $(26,1 \%)$ dibandingkan desa (25,5\%). Untuk Provinsi Riau, berdasarkan profil kesehatan pada tahun 2012 kelompok umur terbanyak dengan kasus hipertensi adalah 45-54 tahun yaitu sebanyak 892 kasus, diikuti oleh kelompok umur 55-59 tahun sebanyak 746 kasus dan kelompok umur 60-69 tahun sebanyak 728 kasus (Dinkes Prov Riau, 2012).

Berdasarkan Data Badan

Kependudukan dan Keluarga Berencana Nasional (BKKBN,2013), Bahwa peserta $\mathrm{KB}$ di Indonesia lebih banyak memilih Kontrasepsi Suntik sebagai alat kontrasepsi yaitu sebanyak 4.128.115 orang $(48,56 \%)$ sedangkan pemakai Kontrasepsi Pil sebanyak 2.261. 480 orang $(26,60 \%)$. Data yang diperoleh dari Dinas Kesehatan Kota Pekanbaru jumlah Akseptor KB pada tahun 2016 sebanyak 131.496 Pasangan Usia Subur (PUS) yang terdiri dari akseptor KB suntik sebanyak 57.140 PUS, pil sebanyak 37.374 PUS,
IUD sebanyak 12.773 PUS, implant sebanyak 10.428 PUS dan kondom 9.591 PUS (Dinkes, 2016).

Alat kontrasepsi yang banyak menjadi pilihan dari PUS ialah jenis alat kontrasepsi suntik. Kontrasepsi suntik merupakan metode kontrasepsi jangka panjang yang daya kerjanya panjang (lama) dan sangat efektif, pemakaiannya sangat praktis, harganya murah, aman dan tidak membutuhkan pemakaian setiap hari atau setiap akan bersenggama. Namun alat kontrasepsi suntik juga mempunyai banyak efek samping seperti perubahan tekanan darah, gangguan haid, depresi, keputihan bertambah, jerawat, perubahan libido, perubahan berat badan, pusing, sakit kepala dan hematoma (Natalia, 2014).

Berdasarkan data dari Dinas Kesehatan Kota Pekanbaru Tahun 2016 metode kontrasepsi yang banyak digunakan di Pekanbaru yaitu Kontrasepsi suntik dengan jumlah 57.140 orang. Pengguna KB suntik terbanyak didapati di Puskesmas Harapan Raya sebanyak 7.795 orang (14,39 persen). Puskesmas Garuda sebanyak 6.207 orang (10,86 persen). Puskesmas Sidomulyo sebanyak 4.280 orang (7,49 persen). Puskesmas Payung Sekaki sebanyak 3.876 orang $(6,78$ persen), dan Puskesmas RI Sidomulyo sebanyak 3.152 orang (5,51 persen).

Puskesmas Harapan Raya terletak di Jl. H. Imam Munandar No.40, Kelurahan Tangkerang Selatan Kecamatan Bukit Raya Pekanbaru, dengan jenis type non-perawatan. Berdasarkan survei awal yang dilakukan peneliti dari tanggal 1 - 3 Februari 2018 di Puskesmas Harapan Raya Pekanbaru pada 10 respoden yang merupakan akseptor KB suntik didapatkan data tekanan darah normal berkisar 100$120 \mathrm{mmHg}$ sebanyak 6 responden dan 4 
responden yang mengalami hipertensi dengan tekanan darah berkisar 135-140 $\mathrm{mmHg}$.

Berdasarkan uraian di atas peneliti tertarik untuk melakukan penelitian yang berjudul : "Hubungan Antara Pemakaian Alat Kontrasesi Suntik dengan Hipertensi pada Akseptor KB Suntik di Puskesmas Harapan Raya Pekanbaru"

\section{METODE PENELITIAN}

Desain penelitian ini menggunakan desain deskriptif, analitik dengan pendekatan cross sectional. Penelitian ini dilakukan di Puskesmas Harapan Raya Pekanbaru pada tanggal 13 - 28 Juli Tahun 2018 dengan populasi yaitu sebanyak 218 orang. Teknik pengambilan sampel menggunakan Accidental Sampling. Total sampel dalam dalam penelitian yaitu 32 orang yang telah memenuhi kriteria inklusi : ibu yang menggunakan alat kontrasepsi suntik..

Instrumen penelitian menggunakan lembar observasi yang diisi oleh peneliti dan . tensimeter untuk mengukur tekanan darah. Analisa bivariat penelitian ini akan menghubungkan variabel independen dan variabel dependen menggunakan uji statistik chi-square dengan $\alpha<0.005$.

\section{HASIL DAN PEMBAHASAN}

Berdasarkan penelitian yang dilakukan pada tangal 13-28 Juli 2018 di Puskesmas Harapan Raya Pekanbaru, dari 32 responden dapat diperoleh data-data mengenai HubunganPemakaian Alat Kontrasepsi Suntik dengan Tekanan Darah Pada Akseptor KB Suntik sebagai berikut:

\section{Tabel 1}

Distribusi Frekuensi Umur Responden di Puskesmas Harapan Raya PekanbaruJuli 2018

\begin{tabular}{|c|c|c|c|c|}
\hline $\begin{array}{l}\text { Varia } \\
\text { bel }\end{array}$ & $\begin{array}{c}\mathbf{M} \\
\mathbf{e a} \\
\mathbf{n}\end{array}$ & SD & $\begin{array}{c}\text { Minim } \\
\text { al- } \\
\text { Maksi } \\
\text { mal }\end{array}$ & $\begin{array}{c}95 \% \\
\text { CI }\end{array}$ \\
\hline Umu & $\begin{array}{l}32 \\
88\end{array}$ & $\begin{array}{c}6,07 \\
3\end{array}$ & $23-44$ & $\begin{array}{c}30,69 \\
- \\
35,06\end{array}$ \\
\hline
\end{tabular}

Hasil analisis didapatkan rata-rata umur akseptor KB suntik adalah 32,88 tahun (95\% CI: 30,69 - 35.06), dengan standar deviasi 6,073. Umur termuda 23 tahun dan umur tertua 44 tahun. Dari hasil estimasi interval dapat disimpulkan bahwa 95 persen diyakini bahwa rata-rata umur akseptor KB suntik adalah diantara 30,69 sampai dengan 35,06 tahun.

Tabel 2. Distribusi Frekuensi Umur Responden di Puskesmas Harapan Raya PekanbaruJuli 2018

\begin{tabular}{c|cc|c|c}
\hline $\begin{array}{l}\mathbf{N} \\
\mathbf{0}\end{array}$ & $\begin{array}{c}\text { Ketagori Umur } \\
\text { (Tahun) }\end{array}$ & $\begin{array}{c}\text { Frekue } \\
\text { nsi } \\
\text { (f) }\end{array}$ & $\begin{array}{c}\text { Persent } \\
\text { ase } \\
(\boldsymbol{\%})\end{array}$ \\
\hline 1. & Remaja & Akhir & 5 & 15,62 \\
2. & $(17-25)$ & & $\mathbf{1 7}$ & $\%$ \\
3. & Dewasa & Awal & 10 & 53,13 \\
& $(\mathbf{2 6}-\mathbf{3 5})$ & & & $\%$ \\
& Dewasa & Akhir & & 31,25 \\
& $(36-45)$ & & & $\%$ \\
\hline & \multicolumn{2}{|c|}{ Total } & $\mathbf{3 2}$ & $\mathbf{1 0 0}$ \\
\hline
\end{tabular}

Berdasarkan tabel 2 dapat diketahui bahwa umur responden di Puskesmas Harapan Raya Pekanbaru mayoritas berumur dewasa awal 26-35 
tahun yaitu sebanyak 17 responden $(53,13 \%)$.

Tabel. 3.Distribusi Frekuensi Pendidikan Respondendi Puskesmas Harapan Raya Pekanbaru Juli 2018

\begin{tabular}{llcc}
\hline $\mathbf{N}$ & & Frekuens & Persentas \\
$\mathbf{0}$ & $\begin{array}{c}\text { Pendidika } \\
\text { n }\end{array}$ & $\begin{array}{c}\text { i } \\
(\mathbf{f})\end{array}$ & $\begin{array}{c}\text { e } \\
(\mathbf{\%})\end{array}$ \\
\hline 1 & SD & 3 & 9,4 \\
2 & SMP & 7 & 21,8 \\
$\mathbf{3}$ & SMA & $\mathbf{1 9}$ & $\mathbf{5 9 , 4}$ \\
4 & PT & 3 & 9,4 \\
\hline & \multicolumn{1}{c}{ Total } & $\mathbf{3 2}$ & $\mathbf{1 0 0}$ \\
\hline
\end{tabular}

Berdasarkan tabel 3 diperoleh hasil bahwa pendidikan responden di Puskesmas Harapan Raya Pekanbaru mayoritas berpendidikan SMA sebanyak 19 responden $(59,4 \%)$.

Tabel 4. Distribusi Frekuensi Pekerjaan Responden di Puskesmas Harapan Raya Pekanbaru Juli 2018

\begin{tabular}{llcc}
\hline No & $\begin{array}{c}\text { Jenis } \\
\text { Pekerjaan }\end{array}$ & $\begin{array}{c}\text { Frekuensi } \\
\text { (f) }\end{array}$ & $\begin{array}{c}\text { Persentase } \\
(\boldsymbol{\%})\end{array}$ \\
\hline $\mathbf{1}$ & IRT & $\mathbf{2 6}$ & $\mathbf{8 1 , 2}$ \\
2 & PNS & 3 & 9,4 \\
3 & Swasta & 3 & 9,4 \\
\hline \multicolumn{2}{r}{ Total } & $\mathbf{3 2}$ & $\mathbf{1 0 0}$ \\
\hline
\end{tabular}

Berdasarkan tabel 4 diperoleh data pekerjaan responden di Puskesmas Harapan Raya Pekanbaru mayoritas pekerjaannya adalah IRT sebanyak 26 responden $(81,2 \%)$.
Tabel 5. Distribusi FrekuensiLama memakai Kontrasepsi Suntik di Puskesmas Harapan Raya Pekanbaru Juli 2018

\begin{tabular}{cccc}
\hline No & Lama & Frekuensi & Persentase \\
& Memakai & $(\mathbf{f})$ & $(\boldsymbol{\%})$ \\
& KB & & \\
& Suntik & & \\
\hline 1 & $<1$ tahun & 10 & 31,2 \\
2 & 1 tahun & 4 & 12,5 \\
$\mathbf{3}$ & $>\mathbf{1}$ tahun & $\mathbf{1 8}$ & $\mathbf{5 6 , 3}$ \\
\hline & Total & $\mathbf{3 2}$ & $\mathbf{1 0 0}$ \\
\hline
\end{tabular}

Berdasarkan tabel 5 diperoleh data lama memakai kontrasepsi suntik responden di Puskesmas Harapan Raya Pekanbaru mayoritas memakai $>1$ tahun sebanyak 18 responden $(56,3 \%)$.

Tabel 6. Distribusi Frekuensi Jenis Penggunaan Kontrasepsi Suntik yang di Gunakan di Puskesmas Harapan Raya Pekanbaru Juli 2018

\begin{tabular}{cccc}
\hline No & $\begin{array}{c}\text { Kontrasepsi } \\
\text { Suntik }\end{array}$ & $\begin{array}{c}\text { Frekuensi } \\
(\mathbf{f})\end{array}$ & $\begin{array}{c}\text { Persentase } \\
(\boldsymbol{\%})\end{array}$ \\
\hline 1 & 1 Bulan & 8 & 25 \\
2 & 3 Bulan & $\mathbf{2 4}$ & $\mathbf{7 5}$ \\
\hline & Total & $\mathbf{3 2}$ & $\mathbf{1 0 0}$ \\
\hline
\end{tabular}

Berdasarkan tabel 6 diperoleh data pengguna kontrasepsi suntik responden di Puskesmas Harapan Raya Pekanbaru mayoritas menggunakan kontrasepsi suntik 3 bulan sebanyak 24 responden (75\%). 
Tabel 7 Distribusi Frekuensi Ibu Yang Mengalami Pusing dan Tengkuk Terasa Beratdi Puskesmas Harapan Raya PekanbaruJuli 2018

Berdasarkan tabel 5.7 diperoleh data Responden yang mengalami pusing dan tengkuk terasa berat di Puskesmas Harapan Raya Pekanbaru adalah sebanyak 17 responden $(53,1 \%)$.

Tabel 5.8. Distribusi Frekuensilbu Yang Mengalami Perubahan Tekanan Darah Selama Menggunakan Kontrasepsi Suntik di Puskesmas Harapan Raya Pekanbaru Juli 2018
Tabel 9. Distribusi Frekuensilbu Yang Memiliki Riwayat Hipertensi di Puskesmas Harapan Raya PekanbaruJuli 2018

\begin{tabular}{cccc}
\hline No & Ibu Yang & Frekuensi & Persentase \\
& Mengalami & & \\
& Pusing dan & $(\mathbf{f})$ & $(\%)$ \\
& Tengkuk & & \\
& Terasa & & \\
& Berat & & \\
\hline $\mathbf{1}$ & Ya & $\mathbf{1 7}$ & $\mathbf{5 3 , 1}$ \\
2 & Tidak & 15 & 46,9 \\
\hline & Total & $\mathbf{3 2}$ & $\mathbf{1 0 0}$ \\
\hline
\end{tabular}

No Ibu Yang Frekuensi Persentase

\begin{tabular}{|c|c|c|c|c|c|c|}
\hline No & $\begin{array}{c}\text { Ibu Yang Mengalami } \\
\text { Perubahan Tekanan } \\
\text { Darah }\end{array}$ & $\begin{array}{c}\text { Frekuensi } \\
\text { (f) }\end{array}$ & & $\begin{array}{c}\text { PeAsentilisi } \\
\text { Rigyyat } \\
\text { Hipertensi }\end{array}$ & (f) & $(\%)$ \\
\hline 1 & $\mathrm{Ya}$ & 11 & 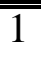 & $\overline{\mathrm{Y}} \mathrm{Y} 4,4$ & 3 & 9,4 \\
\hline 2 & Tidak & 21 & 2 & Tideb & 29 & 90,6 \\
\hline & Total & 32 & & 100tal & 32 & 100 \\
\hline
\end{tabular}

Berdasarkan tabel 8 diperoleh data perubahan Tekanan darah selama menggunakan kontrasepsi suntik di Puskesmas Harapan Raya Pekanbaru mengalami perubahan sebanyak 11 responden $(34,4 \%)$ dan yang tidak mengalami perubahan sebanyak 21 responden $(65,6 \%)$.
Berdasarkan tabel 9 diperoleh dataibu yang memiliki riwayat hipertensi di Puskesmas Harapan Raya Pekanbaru sebanyak 3 responden $(9,4 \%)$ dan tidak memiliki riwayat hipertensi sebanyak 29 responden $(90,6 \%)$.

Tabel 10. Distribusi Frekuensilbu Yang Memiliki Riwayat Hipertensi Saat Hamil di PuskesmasHarapan Raya PekanbaruJuli 2018

\begin{tabular}{llcc}
\hline No & Ibu YangMemiliki & Frekuen & Persentase \\
& RiwayatHipertens & si & \\
& i & $(\mathbf{f})$ & $(\%)$ \\
\hline 1 & Ya & 2 & 6,9 \\
$\mathbf{2}$ & Tidak & $\mathbf{2 7}$ & $\mathbf{9 3 , 1}$ \\
\hline \multicolumn{2}{r}{ Total } & $\mathbf{2 9}$ & $\mathbf{1 0 0}$ \\
\hline
\end{tabular}


Berdasarkan tabel 10 diperoleh dataibu yang memiliki riwayat hipertensi saat hamil di Puskesmas Harapan Raya Pekanbaru sebanyak 2 responden $(6,9 \%)$ dan tidak memiliki riwayat hipertensi saat hamil sebanyak 27 responden $(93,1 \%)$.

\section{Analisis Bivariat}

Tabel 11. Distribusi FrekuensiHubungan Jenis Kontrasepsi suntik dengan Tekanan Darah di Puskesmas Harapan Raya PekanbaruJuli 2018

\begin{tabular}{|c|c|c|c|c|c|c|c|}
\hline \multirow[b]{2}{*}{$\begin{array}{l}\text { Va } \\
\text { ria } \\
\text { bel }\end{array}$} & \multicolumn{7}{|c|}{ Perubahan Tekanan Darah } \\
\hline & $\begin{array}{l}\text { Nor } \\
\text { mal }\end{array}$ & $\%$ & $\begin{array}{c}\text { Hiper } \\
\text { tensi }\end{array}$ & $\%$ & $\begin{array}{l}\text { To } \\
\text { tal }\end{array}$ & $\%$ & $\begin{array}{l}p- \\
v a \\
l u \\
e\end{array}$ \\
\hline $\begin{array}{l}\text { Jeni } \\
\text { s } \\
\text { KB }\end{array}$ & $\begin{array}{c}1 \\
\text { bul } \\
\text { an }\end{array}$ & 8 & 100 & 0 & 0 & 8 & $\begin{array}{c}10 \\
0\end{array}$ \\
\hline $\begin{array}{l}\text { Sun } \\
\text { tik }\end{array}$ & $\begin{array}{c}3 \\
\text { bul } \\
\text { an }\end{array}$ & 17 & $\begin{array}{c}70,8 \\
3\end{array}$ & 7 & $\begin{array}{l}29, \\
17\end{array}$ & $\begin{array}{l}2 \\
4\end{array}$ & $\begin{array}{c}10 \\
0\end{array}$ \\
\hline $\begin{array}{c}\text { Tot } \\
\text { al }\end{array}$ & 25 & $\begin{array}{l}78, \\
13\end{array}$ & 7 & $\begin{array}{l}2 \\
1, \\
8 \\
7\end{array}$ & 32 & $\begin{array}{l}1 \\
0 \\
0\end{array}$ & \\
\hline
\end{tabular}

\section{Berdasarkan tabel 11 tampak bahwa dari 24 responden yang menggunakan kontrasepsi suntik 3 bulan didapatkan $7 \quad(29,17 \%)$ responden mengalami hipertensi, dan berdasarkan statistik tidaak terdapat hubungan yang signifikan antara jenis kontrasepsi suntik dengan tekanan darah, yang dibuktikan dengan nilai $P$-value $>0,05$ yaitu 0,084 .}

Berdasarkan hasil penelitian yang dilakukan peneliti pada tanggal 13 - 28 Juli 2018 di Puskesmas Harapan Raya
Pekanbaru dengan judul "Hubungan antara Pemakaian Alat Kontrasepsi Suntik dengan Tekanan Darah', Membuktikan bahwa tidak ada hubungan yang signifikan antara kontrasepsi suntik dengan tekanan darah yang dibuktikan dengan nilai P-value $>0,05$ yaitu 0,084 . Hal ini terlihat dari 32 responden 25 $(78,13 \%)$ masih mengalami tekanan darah normal.

Hal ini berbeda dengan penelitian yang telah dilakukan oleh Bella, dkk (2017) yang meneliti tentang Hubungan penggunaan alat kontrasepsi suntik Depomedroxi Progesterone Acetat (DMPA) dengan tekanan darah pada ibu di Puskesmas Ranotana Weru, didapatkan hasil bahwa terdapat hubungan yang signifikan antara penggunaan alat kontrasepsi suntik DMPA dengan Tekanan Darah pada Ibu di Puskesmas Ranotana 0,0Weru.

84 Penelitian ini juga berbanding terbalik dengan penelitian yang dilakukan oleh Sanger, dkk (2008) dengan judul penelitian Pengaruh Suntikan DMPA terhadap profil lipid, dimana didapatkan terjadi penurunan kadar HDL-kolesterol setelah 12 bulan pemakaian. Terjadinya penurunan kadar HDL kolesterol akan meningkatkan resiko meningkatnya tekanan darah.

Hasil penelitian menunjukkan hanya $7 \quad(21,87 \%)$ responden yang mengalami hipertensi, hal ini disebabkan karena beberapa faktor yang yang mempengaruhi tekanan darah antara lain usia. Usia yang masih tergolong muda memiliki tekanan darah masih dalam batas normal seiring dengan tingkat kesuburan wanita yang masih tinggi. Wanita yang belum mengalami menopause dilindungi oleh hormon estrogen yang berperan 
dalam meningkatkan kadar High Density Lipoprotein (HDL).

Perbedaan dari hasil analisis tersebut kemungkinan terjadi karena perbedaan indikator penelitian, selain itu hasil penelitian ini kurang cukup untuk menggambarkan keseluruhan populasi karena sedikitnya jumlah sampel dibandingkan keseluruhan pasangan usia subur yang memakai kontrasepsi suntik di Puskesmas Harapan Raya Pekanbaru.

\section{KESIMPULAN}

Berdasarkan hasil penelitian yang dilakukan di Puskesmas Harapan Raya Pekanbaru pada tanggal 13-28 Juli 2018 dengan cara menyebarkan kuesioner dan mengukur tekanan darah pada akseptor KB suntik, maka hasil penelitian ini dapat disimpulkan bahwa pemakaian alat kontrasepsi suntik pada akseptor KB suntik di Puskesmas Harapan Raya Pekanbaru yang paling banyak yaitu pemakaian alat kontrasepsi suntik 3 bulan 24 orang $(75 \%)$ dan Perubahan tekanan darah di Puskesmas Harapan Raya sebanyak 11 orang $(45,83 \%)$ pada pemakaian suntik 3 bulan sedangkan pada pemakaian suntik 1 bulan tidak terjadi perubahan, dan pada penelitian ini dapat disimpulkan bahwa tidak terdapat hubungan yang sinigfikan antara pemakaian alat kontrasepsi suntik dengan tekanan darah pada akseptor KB suntik di Puskesmas Harapan Raya Pekanbaru.

\section{SARAN}

1. Berdasarkan hasil penelitian tersebut terdapat beberapa saran yang dapat di sampaikan peneliti antara lain :

\section{Kepada Peneliti Selanjutnya}

Hasil penelitian ini diharapkan dapat menambah pengalaman bagi peneliti khususnya tentang Hubungan antara Pemakaian Alat Kontrasepsi Suntik dengan Tekanan Darah pada akseptor KB suntik dan bisa menjadi langkah awal untuk melakukan penelitian selanjutnya.

\section{Kepada Pihak Institusi Pendidikan}

Diharapkan untuk dapat menambah buku-buku di perpustakaan khususnya tentang Hubungan antara Pemakaian Alat Kontrasepsi Suntik dengan Tekanan Darah serta media informasi lainnya, sehingga mahasiswa lebih mudah untuk mendapatkan bahan dalam penelitian selanjutnya.

\section{Kepada Ibu-ibu Responden}

Kepada masyarakat di wilayah kerja Puskesmas Harapan Raya Pekanbaru dapat mengetahui hubungan pemakaian kontrasepsi suntik terhadap perubahan tekanan darah, sehingga ibu bisa memilih kontrasepsi suntik yang mempunyai efek samping rendah terhadap peningkatan tekanan darah dan bila ibu yang memakai kontrasepsi suntik mengalami peningkatan tekanan darah dianjurkan supaya mengganti kontrasepsi lain sesuai dengan kondisinya

\section{DAFTAR PUSTAKA}

Aziz,Alimul Hidayat, (2007). Riset Keperawatan dan Teknik Penulisan

Ilmiah Edisi 2. Jakarta : Salemba Medika 
Ardiansyah dan Muhammad Fachri, (2017). Hubungan Penggunaan Kontrasepsi Suntik Bulan Selama Satu Tahun dengan Peningkatan Tekanan Darah. Jurnal kesehatan Masyarakat Fakultas Kedokteran dan Kesehatan Universitas

Muhammadiyah Jakarta

BKKBN, (2013). Pelayanan Kontrasepsi. Jakarta :BKKBN

Departemen Kesehatan RI. (2008). Profil Kesehatan Indonesia. Jakarta : Depkes RI Jakarta.

Departemen Kesehatan Republik Indonesia. Riset Kesehatan Dasar (RISKESDAS) 2007 Penelitian Dan Pengembangan Kesehatan Departemen Kesehatan Republik Indonesia; 2007.

Dinas Kesehatan Provinsi Riau. (2012). Buku Profil Kesehatan Provinsi Riau Tahun 2012. Pekanbaru

Dinas Kesehatan Kota Pekanbaru (2016). Profil Kesehatan Kota Pekanbaru. Pekanbaru

Eviana. S. (2011). Panduan Pemeriksaan Fisik. Jakarta: Salemba Medika.

Gunawan, Ade Sidik, (2015). Hubungan Lama Penggunaan KB Hormonal dan Obesitas dengan Kejadian Hipertensi di wilayah Puskesmas Rembang, Purbalingga. Skripsi S1 Keperawatan Universitas Muhammadiyah Purwokerto.

Handayani, Sri, S.SI.T. (2010). Pelayanan Keluarga Berencana. Yogyakarta: Pustaka Rihama.
Harnawati. (2008). Buku Saku Kontrasepsi dan Kesehatan Seksual.Reproduksi. Jakarta : EGC.

Muttaqin, arif. (2012). Buku ajar Asuhan keperawatan klien dengan gangguan system kardiovaskuler dan hematologi. Jakarta : Salemba Medika

Natalia Chrisma. (2014). Skripsi : Hubungan Pengetahuan dengan Kepatuhan Ibu Pengguna Kontrasepsi Suntik Depo Medroksi Progesteron Asetat (DMPA) di Wilayah Kerja Puskesmas Ranotana Weru Kecamatan Wanea Manado UNSRAT. Manado.

Notoatmodjo, S. (2010). Metodologi Penelitian Kesehatan. Jakarta : Rineka Cipta

Nursalam, (2008). Konsep dan Penerapan Metodologi Penelitian Ilmu Keperawatan. Jakarta : Salemba Medika

Pinasti, Anisa Putri. (2013). Pengaruh Penggunaan Kontrasepsi Suntik Terhadap Peningkatan Berat Badan dan Kenaikan Tekanan Darah Pada Akseptor Keluarga Berencana di Surakarta. Skripsi S1 Farmasi Universitas Muhammadiyah Surakarta

Ririn, Harini. (2010). Perbedaan Pengaruh Pemakaian Kontrasepsi Suntik (cylofem dan Depoprogestin) Terhadap Peningkatan Tekanan Darah pada Wanita Usia Subur di Wilayah Pakisaji Malang. Jurnal Keperawatan Universitas Muhammadiyah Malang

Rizki, Agustina. (2014). Perbedaan Berat Badan Sebelum dan Sesudah 
Menggunakan $\mathrm{Kb}$ hormonal di Puskesmas Ronga- Rongga Banda Aceh. Skripsi Diploma IV Kebidana Universitas U'Budiyah Indonesia Banda Aceh

Saryono, (2010). Metodologi Penelitian Kebidanan. Nuhamedika. Jakarta

Setianingrum, Putri. (2009). Hubungan Antara Pemakaian Alat Kontrasepsi Suntik dengan Tekanan Darah Pada Aksepto KB Suntik di Puskesmas Delanggu klaten. Skripsi S1 Keperawatan Universitas Muhammadiyah Surakarta

Sri Haryanti, rusiana dan agsteria alif'ta.(2017). Analisi Faktor Yang Mempengaruhi Pasangan Usia Subur Dalam Pemilihan Kontrasepsi Suntik Kombinasi dan Progestin. journal on medical science Prodi
DIII Kebidanan STIKES PKU Muhammadiyah Surakarta

Suratun, S. Heryani, \& Manurung, S., 2008, Pelayanan Keluarga Berencana dan Pelayanan Kontrasepsi, Jakarta: Trans Info Media

Suyanto \& Salamah. (2009). Riset Kebidanan : Metodologi dan Aplikasi. Yogyakarta: Mitra Cendikia Press

Tendean Bella, Rina Kundre, Rivelino S. Hamel. (2017). Hubungan Penggunaan Alat Kontrasepsi Suntik Depomedroksi Progesteron Asetat (DMPA) dengan Tekanan Darah Pada Ibu Di Puskesmas Ranotana Weru. Jurnal Keperawatan Fakultas Kedokteran Univrsitas Sam Ratulangi 